\title{
CONTEXTUALISMO LINGUÍSTICO E CRÍTICA HISTORICISTA: COMO COMPREENDER AS IDEIAS DO PASSADO?
}

\section{Camila Massaro de Góes ${ }^{1}$}

\section{Resumo:}

Este artigo apresenta como principal objetivo a reflexão em torno das orientações metodológicas do "contextualismo linguístico" da Escola de Cambridge, com vistas a apreender os principais aspectos da crítica reivindicada pelos historiadores ingleses ao longo da década de 1960. Estes procuravam uma nova perspectiva metodológica que apreendesse adequadamente o contexto e o significado das ideias do passado. Nesse sentido, será chamada especial atenção para Quentin Skinner, considerado o principal autor desta iniciativa, e seu ensaio clássico "Meaning and Understanding in the History of Ideas", publicado em 1969. De modo complementar, busca-se ressaltar um momento das críticas à abordagem skinneriana dentro do campo do "historicismo", desde uma perspectiva marxista, a partir das contribuições de Joseph Femia, seguindo as orientações metodológicas do marxista italiano Antonio Gramsci. Deste modo, buscamos contribuir para a discussão metodológica no âmbito do pensamento político e da história das ideias.

Palavras-chave: Escola de Cambridge, contextualismo linguístico, historicismo, Quentin Skinner.

\section{Resumen:}

En este artículo se presenta como principal objetivo la reflexión sobre las orientaciones metodológicas de "contextualismo lingüístico" de la Escuela de Cambridge, con el fin de comprender los puntos principales de la crítica reivindicada por los historiadores ingleses en toda la década de 1960 . Estos buscaban una nueva perspectiva metodológica que aprehendiese adecuadamente el contexto y significado de las ideas del pasado . En este sentido, se llama especial atención a Quentin Skinner, considerado el autor principal de esta iniciativa , y su clásico ensayo " Significado y comprensión en la historia de las ideas ", publicado en 1969. De manera complementaria, se busca resaltar un momento de crítica del enfoque de Skinner en el campo de " historicismo ", desde una perspectiva marxista, con las contribuciones de Joseph Femia , siguiendo las directrices metodológicas del marxista italiano Antonio Gramsci. De esta manera, se busca contribuir a la discusión metodológica en el pensamiento político y la historia de las ideas.

Palabras-clave: Escuela de Cambridge, contextualismo linguístico, historicismo, Quentin Skinner.

\begin{abstract}
:
This article presents as its main objective the reflection on the methodological guidelines of the Cambridge School's "linguistic contextualism", in order to grasp the main points of the criticism claimed by these English historians throughout the 1960s. They sought a new methodological perspective that could adequately apprehend the context and meaning of the ideas of the past. In this sense we highlight the work of Quentin Skinner, considered the principal author of this enterprise and his classic essay "Meaning and Understanding in the History of Ideas," published in 1969. In a complementary manner, we seek to highlight a moment of criticism of Skinner's approach within the field of "historicism", from a Marxist perspective, with the contributions of Joseph Femia, following the methodological guidelines of the Italian Marxist Antonio Gramsci. This way, we seek to contribute to the methodological discussion within political thought and history of ideas.
\end{abstract}

Keywords: Cambridge School, linguistic contextualism, historicism, Quentin Skinner.

\footnotetext{
1 Bolsista FAPESP de mestrado no Departamento de Ciência Política da Universidade de São Paulo,
} exercendo estágio de pesquisa na Universidade de Princeton nos EUA no segundo semestre de 2013. 
Revista Eletrônica de Ciência Política, vol. 4, n. 1-2, 2013.

$\operatorname{recp} \overline{249}$ 


\title{
1. INTRODUÇÃO
}

O objetivo deste artigo é discutir as orientações metodológicas do chamado "contextualismo linguístico" da Escola de Cambridge, buscando apreender os principais aspectos da crítica reivindicada pelos historiadores ingleses ao longo da década de 1960. Estes procuravam uma nova perspectiva metodológica que apreendesse adequadamente o contexto e o significado das ideias do passado. Nesse sentido, será chamada especial atenção para Quentin Skinner, considerado o principal autor desta perspectiva, e seu ensaio clássico "Meaning and Understanding in the History of Ideas", publicado em 1969. Num segundo momento, nos debruçaremos sobre uma das críticas à esta abordagem, realizada por Joseph Femia em seu artigo An Historicist Critique of "Revisionist" Methods for Studying the History of Ideas (1981). ${ }^{2}$ Com isso, espera-se colocar em relevo o modo pelo qual o contextualismo linguístico influenciou o debate metodológico no âmbito da "história das ideias", assumindo o artigo de 1969 de Skinner como o mais influente nesse aspecto. De modo complementar, busca-se ressaltar um momento das críticas à abordagem skinneriana dentro do campo do "historicismo", desde uma perspectiva marxista, a partir das contribuições de Femia, seguindo as orientações metodológicas do marxista italiano Antonio Gramsci.

Para melhor entender o surgimento da abordagem contextualista linguística se faz necessário, destarte, retomar um pouco do cenário intelectual que a precedeu. Nos primórdios dos anos 1950, o movimento behavioralista, localizado principalmente nos Estados Unidos, buscava evitar a identificação da teoria política com a história das ideias políticas e o estudo de textos clássicos (GUNNEL, 1981, p.7). David Easton, em seu "clássico diagnóstico do empobrecimento da teoria política" argumentava que:

\begin{abstract}
O pensamento político contemporâneo vive parasitariamente em ideias do passado e, o que é mais desanimador, se vê poucas perspectivas de desenvolvimento de novas sínteses políticas. Diz-se que as ciências sociais aguardam um novo Aristóteles [...] Para a teoria política, se as perspectivas atuais são qualquer indicação do turno de eventos futuros, essa espera será em vão, pois não estamos a preparar o solo no qual o pensamento criativo revolucionário surgirá (EASTON, 1951, p.36).
\end{abstract}

Segundo Easton (1951), em fins do século XIX, o interesse acerca da reformulação de valores e de concepções de uma "boa ordem política" diminuiu em favor do varejo de informações sobre o sentido, a consistência interna e o desenvolvimento histórico de valores políticos contemporâneos e passados. Easton argumenta, ainda, que

\footnotetext{
${ }^{2}$ Embora utilize a versão publicada em 1981, vale destacar que esse artigo em 1988 foi incorporado ao livro organizado por James Tully "Meaning and Context: Quentin Skinner and his critics".
} 
houve um declínio da teoria política e sua redução ao "historicismo", manifesto na obra de autores como W.A. Dunning, C.H. McIlwain e G.H. Sabine. Estes historiadores teriam, de acordo com Easton, abordado valores de modo acrítico, com o objetivo de explicar objetivamente "a relação das ideias com o ambiente social e com uma situação histórica específica" (ibid., p. 40-41).

Além do "metodismo" presente nessa década, tendo Easton como um de seus representantes, se deram outras tentativas de explicar o que geralmente era aceito como legado de uma longa tradição da "teoria política ocidental" e o desaparecimento da literatura que a caracterizou (GUNNEL, 1981, p.9-10). Neste sentido, é importante chamar a atenção para as premissas características da ideia de tradição que se desenvolveram enquanto apoio à história da teoria política entendida como um campo de estudos. Em resposta à Easton e à ciência política de seu tempo, Sheldon Wolin contrastou a ideia de "vocação" do teórico político.

Segundo Wolin (2006, p.26), as ideias e conceitos do passado se refinaram ao longo dos séculos e não deveriam ser vistas como um fundo de conhecimento político absoluto, mas antes como um fundo contínuo, que envolve uma gramática e um vocabulário específicos que vem facilitar a comunicação e seu entendimento. Quanto ao desaparecimento desta "tradição", Wolin afirma que "o declínio da filosofia política corresponderia à perda de identidade do domínio público”. Um dos aspectos essenciais do que é propriamente político, nesta perspectiva, seria a sua relação com aquilo que é "público" - o que em grande parte foi legado proveniente da atividade histórica de filósofos políticos (ibid., p. 4, grifos meus). É por essa razão que um entendimento da tradição se torna essencial para compreender a política contemporânea, ou seja, para fazer teoria política ou mesmo ciência política.

Desta forma, historiadores da teoria política definiram e propagaram a ideia de tradição como paradigma de pesquisa e ensino a partir dos anos 1960. Aqui, é preciso enfatizar as contribuições do teuto-americano Leo Strauss, expoente da perspectiva denominada por Skinner como "textualista", alvo principal de suas críticas. Assim como Wolin, Strauss considerava que a filosofia política vivia uma crise profunda e se encontrava em estado de deterioração. Essa decadência teria sido iniciada a partir da emergência do positivismo e do "historicismo" na idade moderna que "negando o conhecimento objetivo dos valores e afirmando a sua total relatividade, destruiu as bases intelectuais desta atividade" (STRAUSS, 1959, p.18). Nesta visão, a crise moderna seria uma consequência do declínio da filosofia política. Daí que o resgate da história dessa filosofia teria como 
principal objetivo a procura pelas raízes da crise ocidental e a tentativa de restauração dos valores anteriormente propagados pela antiga filosofia política, os quais estariam perdidos ou distorcidos.

Embora argumentasse que o resgate da história da filosofia política era de singular importância para a iluminação e solução de problemas políticos contemporâneos, Strauss diferenciava-se dos "historicistas" ao considerar que o estudo do passado tinha um caráter essencialmente prático, e pouco tinha a dizer sobre os critérios de interpretação dos textos que dariam substância à sua procura de objetividade histórica (GUNNEL, 1981, p.53).

Foi ao longo da década de 1960 que a reflexão sobre problemas metodológicos de interpretação dos textos clássicos aumentou de forma notável, e importantes temas filosóficos sobre a compreensão e significado das ideias do passado foram levantados:

Enquanto a literatura característica do mito da tradição tendia a destacar o que deveria ser estudado e por quê, a crítica histórica se concentrava no problema do como e admitia que as questões anteriores eram diferentes e de caráter ancilar (ibid., p.70).

A partir daí foi possível observar uma abrangente "revitalização de estilos de teorização política informados pelo conhecimento histórico" (SILVA, 2009, p.301), acompanhado da reivindicação de um método "verdadeiramente autônomo para estudar a história da teoria política" (POCOCK apud GUNNEL, 1981, p.19). A procura por um conhecimento histórico em sua íntima relação com a teorização política pode ser vista como produto da superação de um contexto em que os teóricos pareciam convencidos do contrário. A questão relevante que passou a conduzir a reflexão era a seguinte - "quais eram os métodos apropriados a serem adotados no intuito de chegar à compreensão de uma obra do passado?” (SKINNER, 1969, p.3).

\section{QUENTIN SKINNER E A CRÍTICA AO SEU “TEMPO": O EMBATE COM O “TEXTUALISMO” E O “CONTEXTUALISMO” NA HISTÓRIA DAS IDEIAS}

Skinner, em seu clássico artigo de 1969, endereçou uma crítica "violenta" às várias tradições da história das ideias políticas, acusando-as, principalmente, de incorrerem no erro comum do anacronismo, ou seja, de imputarem a autores e obras intenções e significados que jamais tiveram, nem poderiam ter tido, em seus contextos originais de produção (JASMIN, 2005, p.27). Desde então, tornou-se praticamente impossível argumentar que grandes textos poderiam ser entendidos simplesmente através de sua leitura, independentemente do que seus autores possivelmente pretendiam dizer ao 
escrevê-los (RUNCIMAN, 2001, p.84). Isso porque os historiadores da Escola de Cambridge estavam convencidos que textos centrais da história do pensamento político não deveriam ser lidos de modo instrumental, bem como não poderiam ser entendidos adequadamente se vistos apenas como uma série de lições de política e moral.

Pocock $^{3}$ (2003), que, junto a Skinner e John Dunn, formou-o núcleo principal da chamada Escola de Cambridge, identifica que foi Peter Laslett quem principalmente influenciou esta nova perspectiva. Embora Laslett tenha anunciado a morte da filosofia política em 1956, foi ele, com os seus trabalhos sobre Filmer e Locke, ${ }^{4}$ quem ensinou sobre “os arcabouços, tanto teóricos quanto históricos" nos quais deveriam se situar as pesquisas sobre a história do pensamento político (POCOCK, 2003, p.25). Foi a partir de então que para Pocock (2003) começava a tomar forma uma historiografia com ênfases bastantes características:

\begin{abstract}
primeiro, sobre a variedade de "linguagens" em que o debate político pode se desdobrar [...] e segundo, sobre os participantes do debate político, vistos como atores históricos, reagindo uns aos outros em uma diversidade de contextos linguísticos e outros contextos históricos e políticos que conferem uma textura extremamente rica à história, que pode ser resgatada de seu debate (ibid., p.25).
\end{abstract}

Desde então, passou a ser necessário redefinir a historiografia do pensamento político e suas implicações, assim como definir sua práxis em termos mais rigorosamente históricos. É importante destacar que a busca por uma compreensão do texto, não só através de contextos históricos e políticos, mas também através de seu contexto linguístico, consiste num aspecto notável dos historiadores de Cambridge (RUNCIMAN, 2001, p. 86). Foi somente em meados da década de 1960, com a primeira publicação dos textos de Skinner que, segundo Pocock (2003), historiadores do pensamento político começaram a estabelecer e expor a lógica de suas próprias pesquisas e a aprofundá-la nas áreas em que elas se aproximavam da "filosofia da linguagem".

Skinner buscou dar uma resposta alternativa, em sua época, à questão de quais eram os métodos adequados para buscar a compreensão de uma obra do passado, independente de sua natureza - filosófica ou literária - em contraposição ao que ele denominou como "duas respostas ortodoxas que embora conflitantes pareciam comandar

\footnotetext{
3 Antes mesmo que Skinner, Pocock havia publicado em 1962 um primeiro artigo sistemático sobre metodologia, The history of political thought: a methodological enquiry no qual chamava a atenção para as visões dominantes da época, as quais ele pretendia endereçar suas críticas. Pocock pretendia ressaltar as atividades que caracterizavam o trabalho do historiador em distinção ao trabalho do filósofo político, a partir de níveis diferentes de abstração.

${ }^{4}$ Em sua edição de Dois Tratados sobre o Governo Civil (1960) de John Locke, Laslett se vale de bibliografias e manuscritos inéditos da biblioteca descoberta do filósofo inglês para formular suas interpretações.
} 
larga aceitação" (SKINNER, 1969, p. 3). A primeira dirigia-se aos tipos de contextualismo ${ }^{5}$ que privilegiavam os "fatores religiosos, políticos e econômicos" como determinantes do significado de qualquer texto. Tais fatores, nessas perspectivas, seriam suficientes para dar "sustentação final" ao entendimento de uma obra. A outra resposta "ortodoxa" é a dos chamados "textualistas", alvo central das críticas de Skinner, que insistiam na autonomia do texto, considerando-o como a única chave necessária para seu próprio entendimento e que, portanto, tornaria dispensável uma tentativa de reconstrução contextual.

O método "textualista" é apontado como "logicamente amarrado" à afirmação de que as obras passadas contêm "elementos atemporais", isto é, ideias ou sabedorias "não datáveis" com "aplicações universais" (ibid., p.4). A maioria dos elementos críticos da argumentação skinneriana é justamente endereçada ao conjunto de erros resultantes desta "crença" em respostas atemporais para perguntas perenes (MINOGUE, 1988, p.177), pois isto afastaria o entendimento das obras de todo contexto histórico considerando a necessidade de demonstrar a "perenidade" dos escritos "clássicos".

Era imprescindível para Skinner buscar as expectativas dos autores considerados "clássicos", isto é, investigar qual era o significado do que disseram em seu contexto. Ao não realizar esse procedimento, seria possível afirmar que um autor está dizendo algo que ele mesmo talvez não aceitasse como seu. Estas leituras não levariam a uma interpretação da história, mas a "absurdos históricos" e mitologias.

O intelectual de Cambridge aponta como a mais constante, neste âmbito, a "mitologia da doutrina", que ocorre quando o historiador é tomado pela expectativa de que cada escritor clássico enuncie alguma doutrina em cada um dos tópicos que constitui seu objeto. Isto pode levá-lo a interpretar notas dispersas e sem tanta relevância como temas centrais de um autor (ibid., p.7). Este erro poderia incorrer em anacronismo, ao passo que um escritor pode ser "descoberto" como "apoiador" de uma visão, em virtude de uma possível semelhança de terminologia, em algum objeto sobre o qual ele não pôde ter pensado em contribuir. Há também o perigo de se afirmar ter "lido" uma doutrina na obra de um escritor que poderia ter pensado em afirmá-la a princípio, mas que de fato não teve

\footnotetext{
5 Trata-se do "contextualismo sociológico, tanto em sua vertente marxista quanto na de Lewis Namier, influente historiador no contexto acadêmico britânico de meados do século XX. Ambas repousariam sobre a confusão entre dois procedimentos intelectuais inteiramente distintos: a determinação causal de uma ideia e a sua compreensão propriamente dita" (SILVA, 2010, p.305).

"A lista de autores atacados por Skinner sob tal rubrica era extensa, destacando-se nomes como os de Leo Strauss, George Sabine e John Plamenatz. A denúncia dos erros textualistas visava também o influente pensador norte-americano Arthur Lovejoy, fundador, em 1940, do Journal of History of Ideas e autor, dentre outros, do clássico The Great Chain of Being, de 1936” (ibid., p. 328).
} 
nenhuma intenção de transmiti-la. Por fim, há ainda o risco de tentar traçar a morfologia de alguma doutrina por todo seu "percurso histórico" - isso levaria a considerá-la como "historicamente imanente". A questão que se coloca nesse âmbito é a seguinte:

\begin{abstract}
se todos os autores que foram colocados como articuladores de certas doutrinas de fato tiveram a intenção de afirmá-las, como eles puderam falhar tanto, a ponto dos historiadores terem que "reconstruir" essas doutrinas através de adivinhações e vagas insinuações? (ibid., p.10).
\end{abstract}

A resposta óbvia, segundo Skinner, é a de que esses autores não pretendiam enunciar tais doutrinas. Com isso, essa mitologia poderia acarretar dois "absurdos históricos". O primeiro, decorrente da tendência em procurar "doutrinas", se trata de uma forma de "não-história", quase inteiramente direcionada a indicar "antecipações" de doutrinas posteriores ao objeto estudado. O segundo, por sua vez, é o decorrente "debate infinito" sobre a possibilidade de se afirmar que certa ideia realmente "emergiu" em um dado tempo, e se está "realmente lá" no trabalho de alguns escritores.

A segunda mitologia enunciada por Skinner é a denominada "mitologia da coerência" e surge quando historiadores tentam forçosamente "fechar" um sistema na obra de autores clássicos, ou mesmo forçar um entendimento estritamente coerente de toda sua obra com isso, se tornaria obrigatório para o autor ter uma "coerência interna" e um "dever" para o historiador revelar esta coerência (ibid., p.16 - 22).

A terceira mitologia é a da "prolepse", quando o historiador está mais interessado na significação retrospectiva de certa obra histórica do que no seu significado para o próprio agente do trabalho. A característica dessa mitologia está na discrepância entre o significado que um observador pode dizer encontrar em dada afirmação e o significado real da mesma (ibid., p.22-24).

Por fim, Skinner enuncia a "mitologia do paroquialismo", que ocorre quando o historiador segue padrões de classificação atuais e ao identificar alguma familiaridade em um "mundo passado", que não lhe é comum, constrói uma "identidade entre o universo mental do autor do passado e o seu próprio universo atual de crenças, produzindo uma falsa familiaridade entre culturas muito distintas” (SILVA, 2010, p.304).

O que une todas essas "mitologias" seria a produção de interpretações "anacrônicas", mediante as quais são atribuídas ideias e intenções a determinado autor, cujos recursos linguísticos e expressivos eram ainda indisponíveis no contexto histórico no qual foram feitas (ibid., p.304). 
Nessa perspectiva, considera-se tortuoso concentrar o foco de uma pesquisa nas formas das palavras envolvidas no texto. Não seria possível entender uma determinada ideia, desta forma, mesmo dentro de um período cultural e histórico bem delimitado, ao passo que diversas palavras podem denotar a mesma ideia com intenções variáveis, bastante incompatíveis. O grande erro consiste, para Skinner, em olhar o "significado essencial" da "ideia" simplesmente como algo que deve, necessariamente, "permanecer o mesmo", e em pensar que existem significados "essenciais" para os quais certos escritores contribuem (SKINNER, 1969, p.37):

\begin{abstract}
Assim que vejamos que não há ideia determinada a que vários escritores tenham contribuído, mas apenas uma variedade de declarações feitas com as palavras por uma variedade de diferentes agentes com uma variedade de intenções, então o que estamos vendo é igualmente que não existe uma história da ideia para ser escrita, mas apenas uma história necessariamente focada sobre os diversos agentes que usaram a ideia, e sobre as diferentes situações e intenções da sua utilização (ibid., p.38).
\end{abstract}

Compreendendo que não há como uma "ideia" prevalecer com o mesmo significado ao longo do tempo, se poderia afirmar que não é possível que vários autores tenham contribuído, ao longo de períodos históricos distintos, para um desenvolvimento desta "ideia". O que existe é uma série de afirmações, através de palavras, por diferentes autores com intenções variadas, e é por isso que uma "história de um conceito" não pode ser traçada - no máximo, é possível entender qual foi a intenção de um agente ao empregar tal "ideia” em situações específicas (ibid., p.39).

Quanto ao método contextualista, Skinner considera que o conhecimento do contexto social de fato oferece uma ajuda considerável para evitar os efeitos anacrônicos que as mitologias enunciadas anteriormente poderiam acarretar. No entanto, pode configurar uma "armadilha", ao passo que ao invés de servir como guia para a compreensão de um autor pode suscitar confusões ainda maiores no âmbito da historia das ideias (ibid., p.40-43).

Para Skinner, a concepção de que as intenções de um autor são estritamente ligadas às suas ações parece criar uma confusão entre duas coisas diferentes, nas quais o conceito de intenção poderia ser aplicado de forma válida:

A distinção, em suma, é entre a intenção "para fazer $\boldsymbol{x}$ " que pode nunca se transformar com êxito em uma ação [...] e a intenção “ao fazer $\boldsymbol{x}$ ”, que não apenas pressupõe a ocorrência da ação relevante, mas é logicamente ligado a ela, no sentido de que serve para caracterizar qual era o seu objetivo (ibid.,p.45). 
A intenção "para fazer x" é a intenção inicial da ação, já a intenção "ao fazer x" é a realização da ação concreta. A intenção em seu segundo sentido é o que Skinner acredita dever ser estudado se quisermos compreender corretamente a ação. O historiador aponta ainda, em sua crítica aos "contextualistas", o erro em identificar o significado de "compreensão" e "explicação" de um texto. Isso porque, através da demonstração de J.L. Austin, ${ }^{7}$ o significado de uma afirmação não deve se prender somente àquilo que foi pronunciado, pois ele também possui fontes de entendimento naquilo que não foi "verbalizado", em sua "força ilocucionária". Mesmo que seja possível compreender o significado de uma afirmação de um autor através do entendimento de seu contexto social, não seria possível perceber sua dimensão "ilocucionária”, o que para Skinner é continuar sem apreender de fato o texto. Em suma, o núcleo da crítica skinneriana é que o estudo do contexto social dos textos mesmo que possa servir para explicá-los, não é o suficiente para compreendê-los. Isso porque o autor pode ter tido uma intenção diferente daquela transmitida, e o uso dos termos pode não estar "adequado" ao uso normal daquele contexto, então não seria possível compreender qual era a intenção real do autor naquele momento.

\section{PROPOSIÇÕES METODOLÓGICAS E A CRÍTICA HISTORICISTA DE JOSEPH FEMIA}

No que se refere ao método proposto por Skinner, a primeira conclusão positiva é a de que a compreensão dos textos pressupõe a compreensão tanto do que eles tinham a intenção de dizer, quanto do como este significado destinava-se a tomar. Daqui resulta que, para entender um texto, deve-se entender tanto a intenção de ser compreendido, quanto o propósito que esta intenção deveria ter, que o próprio texto como pretendido ato de comunicação deve, pelo menos, ter incorporado. Isso significa que, para compreender um texto, devemos saber tanto qual era a intenção do autor de "ser entendido", como também a intenção do "que deveria ser" entendido pelo leitor. A questão que deveria ser colocada no estudo de qualquer texto seria a seguinte: "o que o autor, escrevendo no tempo histórico em que ele escreveu e para o público ao qual ele endereçou seus estudos, poderia ter, na prática, intencionado comunicar através de suas afirmações?” (ibid., p.49).

\footnotetext{
${ }^{7}$ Como aponta Silva (2010), "era natural que Skinner recorresse às contribuições dos filósofos da linguagem que mobilizaram a noção wittgensteiniana de significado para a elaboração da teoria dos atos de fala (speech acts theory). Dentre tais contribuições, Skinner destaca as de J. L. Austin, esboçadas no volume postumamente publicado sob o sugestivo título How To Do Things with Words. Austin desafiava a crença de que os enunciados linguísticos devem ser estudados exclusivamente a partir de suas funções "constatativas", ou seja, a partir do que representam como descrição (que pode ser avaliada como verdadeira ou falsa) de determinado estado de coisas" (SILVA, 2010, p.307).
} 
Para Skinner, uma "condição essencial" para a compreensão de um texto é poder recuperar essa intenção do autor. O método apropriado deveria se preocupar, primeiramente, em delinear todo o conjunto de informações que podem ter sido enunciadas, em dada ocasião, pela declaração de certa afirmação. Em seguida, o método deveria traçar as relações entre o que foi declarado e seu amplo contexto linguístico, de forma a elaborar qual seria a intenção real do autor estudado.

A segunda conclusão positiva é a de que os estudos históricos jamais devem procurar "problemas perenes" ou "verdades universais":

\begin{abstract}
Exigir da história do pensamento uma solução para os nossos próprios problemas imediatos é, portanto, comprometer uma abordagem metodológica não apenas a falácia, mas a algo como um erro moral. Todavia, para aprender com o passado - e nós não podemos apreendê-lo em tudo - aprender a distinção entre o que é necessário e o que é meramente produto das nossas próprias disposições contingentes é a chave para o próprio auto-conhecimento (ibid., p.53).
\end{abstract}

A argumentação de Skinner (1969) parte do pressuposto de que seria possível "recuperar" as intenções originais ${ }^{8}$ dos autores no mesmo momento da escrita, atravessando as camadas de interpretação que se põem entre o texto estudado e o mundo mental do historiador. Joseph Femia é um exemplo, no âmbito do marxismo, da crítica realizada à abordagem contextualista linguística no que diz respeito a sua "filiação epistemológica". O crítico da Escola de Cambridge considera Skinner um "positivista", isto é, "alguém que pretendia retomar a hermenêutica romântica empregada durante o século XIX, através da qual pensava-se ser possível compreender as intenções dos autores em seus próprios termos, e não nos termos peculiares às suas próprias situações e experiências" (SOUZA, 2008, p. 16).

Dentre as críticas endereçadas a Skinner, nos parece interessante destacar o objetivo de Femia em afirmar no pensamento skinneriano ${ }^{9}$ um grande débito com a tradição historicista. Embora dificilmente uniforme, segundo Femia, esta tradição compreende quatro características logicamente interligadas:

\footnotetext{
${ }^{8}$ John Dunn em The Identity of the History of Ideas (1968) enfatiza que "o problema da interpretação é sempre um problema de fechar o contexto. O que fecha o contexto na atualidade é a intenção (e, de modo muito mais abrangente, as experiências) do autor" (p.98-99). Grande parte da argumentação de Skinner é um aprofundamento dos pressupostos metodológicos e críticos já presentes na argumentação de Dunn (1968).

${ }_{9}^{9}$ Femia se endereça ao artigo Meaning and Understanding de 1969, pois embora reconheça que a argumentação skinneriana tenha sido mais e melhor elaborada ao longo dos anos, Skinner nunca teria repudiado os principais pontos de sua argumentação no artigo de 1969 e, portanto, lhe serve como ponto de partida para a crítica.
} 
a) os homens transformam-se por seus próprios esforços para compreender o mundo e adaptá-lo às suas necessidades [...] não há, portanto, uma natureza humana fixa e imutável [...]; (b) [...] não existem normas absolutas através das quais coisas e pessoas possam ser avaliadas [...]; (c) todas as ideias e valores são produtos de uma determinada época histórica [...] todo filósofo é cria de seu tempo [...]; (d) as formas de experiência humana, incluindo obras de arte ou de filosofia, devem ser compreendidas/avaliadas não em termos de princípios eternos, mas em relação às escalas de valores e regras de pensamento adequados às suas especificidades próprias (FEMIA, 1981, p.116).

Para Femia, a afinidade da metodologia skinneriana com esta tradição historicista é clara. No entanto, tendo descartado a possibilidade das ideias passadas poderem sobreviver ao processo de tradução para culturas díspares, Skinner trata as ideias de nossos ancestrais "como fenômenos puramente históricos, sempre trancados em seus contextos determinados" (ibid., p.116). A metodologia proposta por Skinner assumiu exigir, nesse aspecto, uma disjunção radical entre o passado e o presente. Para Runcinman (2001), trata-se de uma verdade "óbvia" que todas as ideias sobre política e moral são provenientes de algum lugar, e que é inteiramente legítimo ler textos do passado na esperança de achar de onde elas vêm (RUNCINMAN, 2001, p. 90) e é esse aspecto da crítica realizada por Femia que se busca principalmente concentrar a atenção.

Assim como Runcinman, Femia argumenta que as ideias podem conservar na memória muito do que é de valor permanente, ainda que sejam obsoletas ou falsas. Para o crítico marxista, pensadores de fato trabalham dentro de tradições intelectuais e - até certo ponto - podem transcender contextos particulares, sendo que toda história é "história contemporânea" - e também política - ditada pelos interesses do historiador.

Em contraposição à Skinner, para Femia o estudo do passado só é valioso na medida em que lança luz sobre os problemas ou necessidades atuais e, nesse sentido, não é nem necessário nem desejável, a partir de uma perspectiva historicista, compreender um corpo de pensamento pura ou principalmente em termos dos projetos conscientes do autor (FEMIA, 1981, p.115). Segundo Femia, Skinner avançou nas seguintes proposições:

\footnotetext{
(i) na esfera da realidade política e social não existem verdades universais ou questões perenes, todo sistema de ideias corresponde a fases específicas e a ordens de experiência; (ii) o pensamento do passado deve ser completamente dissolvido em seu contexto preciso [...]; (iii) o historiador não deve se relacionar com o significado presente ou com a validade das ideias do passado [...] (iv) historicidade demanda que nós foquemos no que o autor conscientemente teve a intenção de dizer; e (v) nenhuma consideração subsequente de uma iniciativa de um pensador poderia sobreviver à demonstração, dependendo da utilização de um critério anacrônico de descrição e de classificação [...](ibid., p.114-115).
}

Assim, a abordagem historicista é considerada "essencialmente correta" (ibid., p.121) por Femia, que busca demonstrar que esta apenas compromete a primeira 
proposição dentre as cinco avançadas por Skinner e apenas em sua forma modificada. Segundo o crítico, as ideias não caem do céu - são formadas em circunstâncias determinadas e como todos os produtos da atividade humana, são formadas em circunstâncias dadas e em razão de certas necessidades. No entanto, o contextualismo linguístico teria ido "longe demais", na medida em que a existência de alguns problemas perenes, sempre subjacentes sobre determinadas faixas de problemas particulares e concretos, tendem a se repetir como explícitos focos de preocupação - e aceitar esse ponto não compromete seu lugar em toda estrutura historicista.

Os problemas perenes seriam tais como quem deve governar, porque e de que forma. Aceitar, portanto, "necessidades e utilidades da vida social" universais é conceder "às instituições, aos costumes, trabalhos de arte e filosofias do passado que continuem a falar conosco" - podendo, assim, ter alguma influência no presente. O crucial para Femia, nesse aspecto, é o nível de abstração no qual se situa um discurso - "quando reivindicamos que não há 'problemas perenes' na filosofia, queremos dizer que certas formas de questões permanentes serão determinadas por uma cultura ou período particular" (ibid., p.123).

Desta forma, de acordo com a perspectiva "historicista" defendida por Femia, a história do passado, de modo oposto à ideia de "crônica morta" ou "fonte de material" só poderia ser escrita com e para os interesses do presente. Em sua argumentação, Femia segue as orientações metodológicas de Antonio Gramsci, que em polêmica com Benedetto Croce, assumiu como um princípio a identificação crociana entre filosofia e história. No entanto, o marxista italiano foi além e concebeu essa identidade também entre história e política e, portanto, entre política e filosofia (KANOUSSI, 2007, p.25). Em um parágrafo intitulado "Como estudar a história?" afirmou ser necessário o conhecimento de todo um processo histórico para dar conta do presente, bem como para dar certa verossimilhança para as previsões políticas do presente se tornarem concretas (GRAMSCI, 1975, p. 1723). Para enfrentar a cisão, realizada por Croce, entre filosofia e política, Gramsci realizava a defesa do historicismo absoluto como método.

Após distinguir aquilo que é social ou "histórico" de uma determinada filosofia, que corresponde à uma exigência da vida prática, seria possível observar ainda um "resíduo" que não pode ser explicado pelo contexto social. É fato, para Gramsci, que uma exigência histórica seja concebida por um filósofo "individuo" de modo pessoal, e que a personalidade particular do filósofo incida profundamente sobre a forma concreta e expressiva de sua filosofia e a importância dessa individualidade é inegável (ibid., p.1272- 
1273). O significado dessa importância, contudo, não é puramente instrumental ou funcional, dado que se é verdadeiro que a filosofia não se desenvolve de outra filosofia, mas é uma solução contínua dos problemas que o desenvolvimento histórico propõe, é também verdadeiro que o filósofo não pode negligenciar os filósofos que o tenham precedido, mas, ao contrário, operem propriamente como se sua filosofia fosse uma polêmica ou um desenvolvimento das filosofias precedentes, das obras individuais concretas das filosofias precedentes (ibid., p.1273).

Deste modo, uma fixação "quase religiosa" nas intenções dos autores só poderia empobrecer a aproximação historicista do campo da história das ideias, diminuindo a capacidade de se aprender com os antepassados, tanto em suas falhas quanto em seus sucessos (FEMIA, 1981, p.130-131). Assim, Femia afirma que se levadas à risca as instruções de Skinner, nunca se poderá produzir "história contemporânea", e, portanto, "história política" isto é, o "conhecimento histórico que tem como caixa de ressonância e haste de medição as preocupações e interesses contemporâneos" (ibid., p.13). Assim, segundo a argumentação do crítico marxista, se torna implausível a visão de conceituação política presente na afirmação de Skinner de que "devemos fazer nosso pensamento por nós mesmos" (SKINNER, 1969, p.52), pois seu método pressupõe uma separação entre o que é "valioso" e o que é "errôneo" ou "transitório", não possibilitando, dessa forma, o aprendizado do passado através do exame das tendências históricas, das comparações trans-históricas, da imposição de sistemas ou do descobrimento de suposições "subterrâneas ou inconscientes". Segundo Femia, isso é um "pseudoproblema" para Skinner ao passo que, para ele, as ideias de nossos ancestrais estão, para todos os intentos e propósitos, "extintas" (ibid., p.134).

\section{CONSIDERAÇÕES FINAIS}

Tanto a crítica ao seu tempo, quanto as proposições metodológicas de Skinner, foram amplamente discutidas internacionalmente, gerando um debate no âmbito da história das ideias que se estende aos dias atuais. A crítica skinneriana e da "Escola de Cambridge" de um modo mais geral, pode ser vista como "vitoriosa" com o aparente "consenso" suscitado na história intelectual quanto à importância de situar o texto em seus diversos contextos. O enfoque na intenção como critério de fechamento do contexto e na aparecente separação radical entre o passado e o presente foram motivos de polêmicas e severas críticas à argumentação skinneriana. A intenção deste artigo foi destacar a importância da 
contribuição de Skinner, tanto no que concerne a radicalidade quanto a originalidade de seu argumento no artigo de 1969, bem como salientar algumas implicações críticas de sua obra, com o artigo de Joseph Femia e sua interpretação "historicista absoluta" baseada nos pressupostos gramscianos. Com isso, espera-se ter contribuído para a reflexão metodológica acerca do embate de ideias no âmbito da história intelectual contemporânea.

\section{REFERÊNCIAS BIBLIOGRÁFICAS}

DUNN, John. The identity of the history of ideas. Philosophy, vol. 43, n. 164, 1967.

EASTON, David. The Decline of Modern Political. The Journal of Politics, Vol. 13, No. 1 (Feb., 1951).

FEMIA, Joseph. An Historicist Critique of "Revisionist" Methods for Studying the History of Ideas. History and Theory, Vol.20, no 2, 1981.

GUNNEL, John. Teoria Política. Brasília: Editora Universidade de Brasília, 1981.

GRAMSCI, Antonio. Quaderni del Carcere; Turim: Einaudi, 1975, v.2; v.3.

JASMIN, Marcelo. História dos Conceitos e Teoria Política e Social: referências preliminares. Revista Brasileira de Ciências Sociais, Vol. 20 nº. 57, 2005.

KANOUSSI, Dora. Los Cuadernos filosoficos de Antonio Gramsci: de Bujarin a Maquiavelo. Ciudad de Mexico: Plaza y Valdés, 2007.

MINOGUE, Kenneth. Method in intellectual history: Quentin Skinner Foundations. In:

Tully, J. (ed.) Meaning and Context: Quentin Skinner and his critics, Cambridge: Polity Press, 1988.

POCOCK, J.G.A. The history of political thought: a methodological enquiry. In: Laslett, P. \& RUNCIMAN, W. G. (eds.) Philosophy, Politics and Society, Second Series. Oxford: Blackwell, 1962.

RUNCINMAN, David. History of political thought: the state of the discipline. British Journal of Politics and International Relations. Vol. 3, n. 1, 2001.

SILVA, Ricardo. História Intelectual e Teoria Política. Revista de Sociologia e Política, v. 17, n. 34, 2009.

O Contextualismo Linguístico na História do Pensamento Político: Quentin Skinner e o Debate Metodológico Contemporâneo. DADOS - Revista de Ciências Sociais, Rio de Janeiro, vol. 53, nº 2, 2010, pp. 299 a 335. 
SKINNER, Quentin. Meaning and understanding in the history of ideas. History and Theory, vol. 8, n. 1, 1969.

SOUZA, Vanderlei Sebastião. Autor, Texto e Contexto: a História Intelectual e o 'Contextualismo Linguístico' na perspectiva de Quentin Skinner. Revista de história e estudos culturais. Vol. 5, ano V, no 4, 2008.

STRAUSS, Leo. What is political philosophy?. Chicago: The University of Chicago Pres, 1959.

WOLIN, Sheldon S. Politics and vision: continuity and innovation in Western political thought.

Princeton: Princeton Univ., 2006. 